\title{
The use of color distribution analysis for ripeness prediction of Golden Apollo melon
}

\author{
Usman Ahmad \\ Department of Mechanical and Biosystem Engineering, Faculty of Agricultural Engineering and Technology, \\ Bogor Agricultural University (IPB), Darmaga Campus, Bogor 16682, Indonesia.E-mail: usmanahmad@ipb.ac.id
}

\begin{abstract}
Human visual perception on color of melon fruit for ripeness judgement is a complex phenomenon that depends on many factors, making the judgement is often inaccurate and inconsistent. The objective of this study is to develop an image processing algorithm that can be used for distinguishing ripe melons from unripe ones based on their skin color. The image processing algorithm could then be used as a pre-harvest tool to facilitate farmers with enough information for making decisions about whether or not the melon is ready to harvest. Four sample groups of Golden Apollo melon were harvested at four different harvesting age, with 55 fruits in each group. The color distribution as results of the image analysis can be separated at the first two groups from other groups with minimal overlap, but they cannot be separated from the other two groups. The color image analysis of the melons in combination with discriminant analysis could be used to distinguish between harvesting age groups with an average accuracy of $86 \%$.
\end{abstract}

Key words: Melon, skin color, ripeness prediction, image processing

\section{Introduction}

Indonesia has many different tropical fruits grown in various regions throughout the country. Melon is one such fruit, famous for it's sweet and pleasant taste, which is high in demand especially in dry season. Production of melon in Indonesia has increased from around 85 thousand tonnes in 2010 to 104 thousand tonnes in 2011, and to 125 thousand tonnes in 2012 and 2013. While in 2014, total production of melon was more than 150 thousand tonnes with Golden Apollo (a honeydew type melon) being one of the most praised melon varieties (Indonesia Beurau of Statistics, 2015).

As a non-climacteric fruit, melon needs to be harvested when it is already in ripe stage. As a consequence, melon farmers need to harvest daily during the season because melons do not ripen all at the same time. Such selection is an acquired skill without which the farmers would tend to receive lower prices for their melons when the collectors do the total soluble solids (TSS) spot checks to determine ripeness level. Human visual perception of a melon's color or ripeness is a complex phenomenon that depends on many, internal and external factors. One very important internal factor is an individual farmer's visual perception which is usually varies among others. Among the external factors are the composition of the object in relation to light reflectance, illumination environment, the distance and angles of illumination, and viewing position.

For many people as buyers' point of view, appearance is a primary criterion when making food purchases (Kays, 1991). This phenomenon is particularly strong for fresh fruit and vegetables. Thus, appearance is a primary determinant for judging product quality throughout the production, storage and marketing process (Kays, 1999). Product appearance is typically evaluated by such charcateristics as size, shape, form, color, freshness and absence of visual defects (Costa et al., 2011). Of these characteristics, color is a particularly important sensory attribute of product quality, because color is closely associated with such quality factors as freshness, and maturity. Therefore, color is an important grading criteria for most food, especially fresh products (Kays, 1999; McCaig, 2002). A number of reports have used image processing to evaluate various agricultural products such as coffee bean quality (Soedibyo et al., 2010), development of a citrus grading machine (Ahmad et al., 2010) and building a vision system to monitor harvested paddy grain quality during head-feeding combine harvester operation (Mahirah et al., 2015).

Normally, consumers initially judge a food product by its color, followed by other attributes such as taste and/or aroma. That is why the color of fresh products affects consumer purchase decisions (Pallottino et al., 2003; Iqbal et al., 2010). Thus, research to objectively assess food color is a field with a growing number of applications (Blasco et al., 2003; Rocha et al., 2003; Quevedo et al., 2010; Cubero et al., 2011). With these increasing consumer requirements for high quality products, the food industry continues to search for more effective systems to rapidly and objectively assess color and non-destructively predict the quality of fruits and other products. Therefore, the development of portable systems to automatically and non-destructively make color assessments and predict quality is vitally necessary.

The objective of this study is to develop an image processing algorithm that can be used for distinguishing ripe melons from unripe ones based on their skin color. The image processing algorithm could then be used as a pre-harvest tool to facilitate farmers with enough information for making decisions about whether or not the evaluated melon is ready to harvest.

\section{Materials and methods}

Four sample groups of Golden Apollo melon were obtained from a farmer in Sragen District, Central Java Province, and 
categorized according to harvesting age (46, 53, 60, and 67 Days After Planting or DAP, with 55 fruits in each group). At first, each melon group was placed in an enclosure $\left(0.7 \times 0.5 \times 0.8 \mathrm{~m}^{3}\right)$ made from plywood and white thick clothe at one side, with four $5 \mathrm{~W}$ $235 \mathrm{~lm}$ daylight Philips lamps located at each of the four upper corners to illuminate inside the enclosure (Fig. 1a). A black clothe was placed on the bottom, while the insides of the enclosure were covered by white paper and white clothe at one side.

Images of the melon were captured using a DFK21BUCO3 (The Imaging Source Asia Co., Ltd., Taiwan) with 2.8-12 mm CSmount lens (Computar) color CCD camera mounted $0.4 \mathrm{~m}$ above the floor of the enclosure, and saved in jpeg format with a 744 by 480 pixels resolution. After the images had been captured, the TSS was measured using a PR-210 type Atago refractometer (Atago
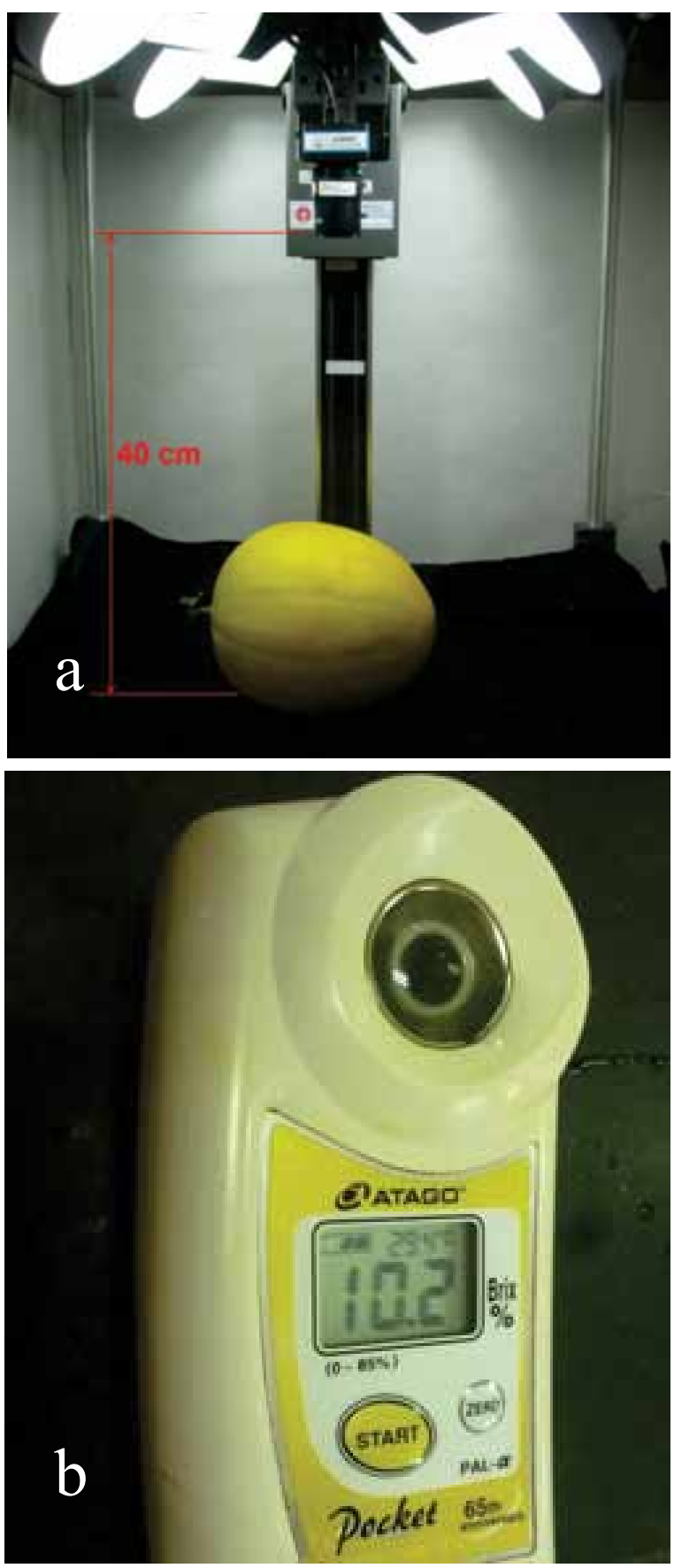

Fig. 1. Apparatus; (a) camera configuration for image acquisition and (b) pocket refractometer for total soluble solid measurement
Co. Ltd., Tokyo, Japan) (Fig. 1b) at three different locations: (1) the upper, (2) middle, and (3) bottom parts of the fruit. An image processing computer program was developed using OpenCV, an open source program development kit, runnning on a Windows platform to analyze the captured images.

Initial analysis of the captured images consisted of binarization and binary opening operation to remove noise, and masking of the color image with the resulted binary image to eliminate the background. The binarization was performed by converting the color image to grayscale, and assigned as an object if the pixel
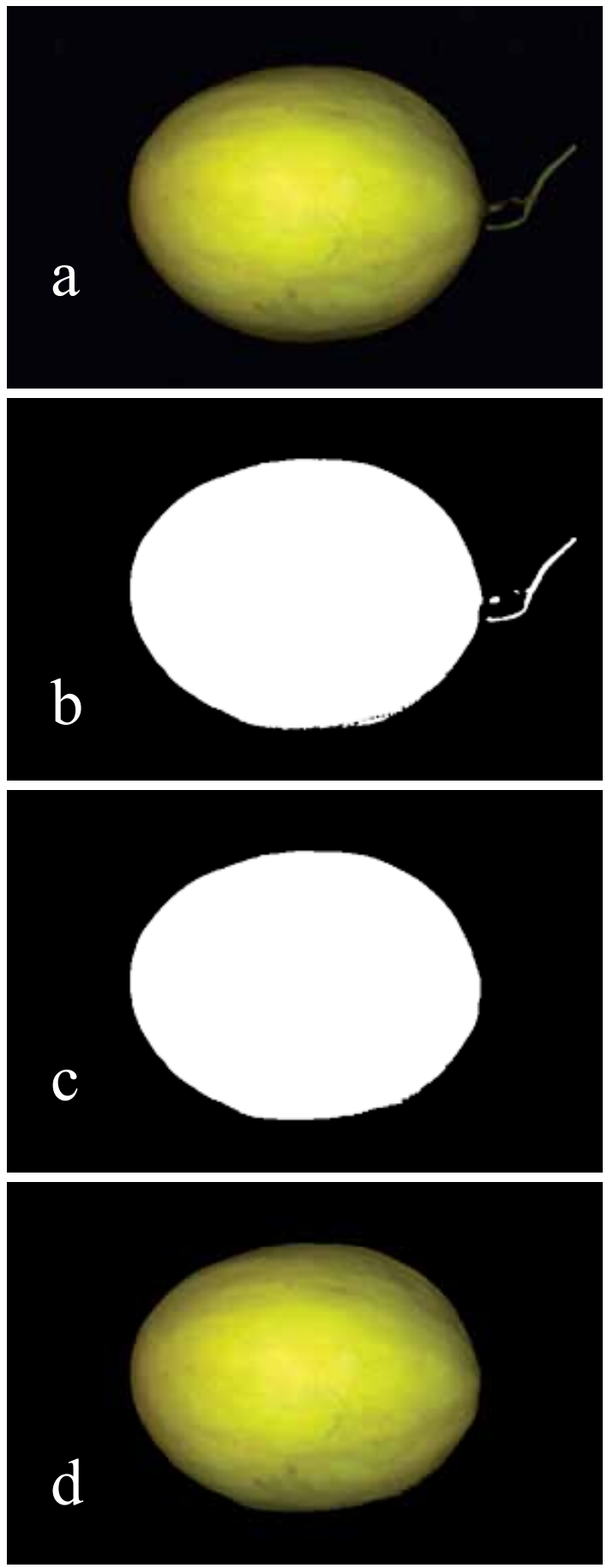

Fig. 2. Image processing applied to extract color of melon fruits; (a) original color image of melon captured by CCD camera, (b) binary image obtained by grayscale thresholding, (c) binary image after opening and closing with 7 by 7 pixels structuring element, and (d) result of masking for background elimination prior to color extraction. 
intensity was 60 or more to create the binary image. To remove the fruit stem, an opening operation using a structuring element of 7 by 7 pixels was conducted on the binary image, followed by closing operation using the same structuring element to keep object original size. Then the resulting clean binary image from these operations was used to obtain a color image of the melon minus the background by masking the binary image into the original image, as shown in Fig. 2. Finally, the color of the fruit in normalized RGB (red-green-blue symbolized by R, G, and B) and HSI (hue-saturation-intensity symbolized by $\mathrm{H}, \mathrm{S}$, and I) color models were extracted from the masked image. The resulting of color distribution in each image was used to identify parameters that were correlated with harvesting ages and fruit sweetness (as measured TSS of the melon flesh). The two color distributions (RGB and HSI) of the melons were determined and processed using discriminant analysis to search for color attributes that can be used to distinguish melon according to harvesting age (DAP), for real-time field applications just before harvest as a final goal of this research.

\section{Results and discussion}

The relationship between average color values in RGB color model and harvesting age are shown in Fig. 3, and relationship between average color values in HSI color model are shown in Fig. 4.

The values of RGB components were displayed after normalization to 0 to 1 range. From the figures, it was clear that the red component of the RGB color model increased with harvesting age, though the incremental increase declined from harvesting age 60 to 67 DAP. The green component showed no clear differences between harvesting ages, while the blue component responded opposite to that of the red; decreasing with increased in harvesting age. This indicated that the color of melon skin changed from a blueish-green to a reddish-green as harvesting age increased. However, the change from 60 to 67 DAP was less than that of 46 and 53 DAP. Similar phenomena are also shown in HSI color model in Fig. 4, where values of hue and saturation showing relationships with harvesting ages, while intensity showed positive relationship with high overlapping. A similiar phenomenon was observed for TSS values, as shown in Fig. 5. The TSS increased rapidly from 46 to 60 DAP, but flattened off from 60 to $67 \mathrm{DAP}$, indicating the melons were already entering the ripening stage by 60 DAP. Ahmad (2013) has reported similar TSS values when a non-climacteric fruit such as melon when it enters the ripening stage. From a harvest point of view, it is recommended that Golden Apollo melon be harvested between 60 and 67 DAP, and they are good quality at this stage of ripening for distribution before consumption.

The image analysis for the two color models are shown in Fig. 6 to Fig. 7. In the RGB color model as shown in Fig. 6 to Fig. 7, it can be seen that the green and blue components of the melons could be separated at 46 and 53 DAP groups from other groups with minimal overlap, but they could not be separated from the other two groups (60 and 67 DAP). Therefore, the RGB color distribution could not be used to distinguish melons at 60 and 67 DAP, because they were all grouped together. The same phenomenon was also observed in the HSI color model model (Fig. 8 and Fig. 9), where, hue and saturation components could
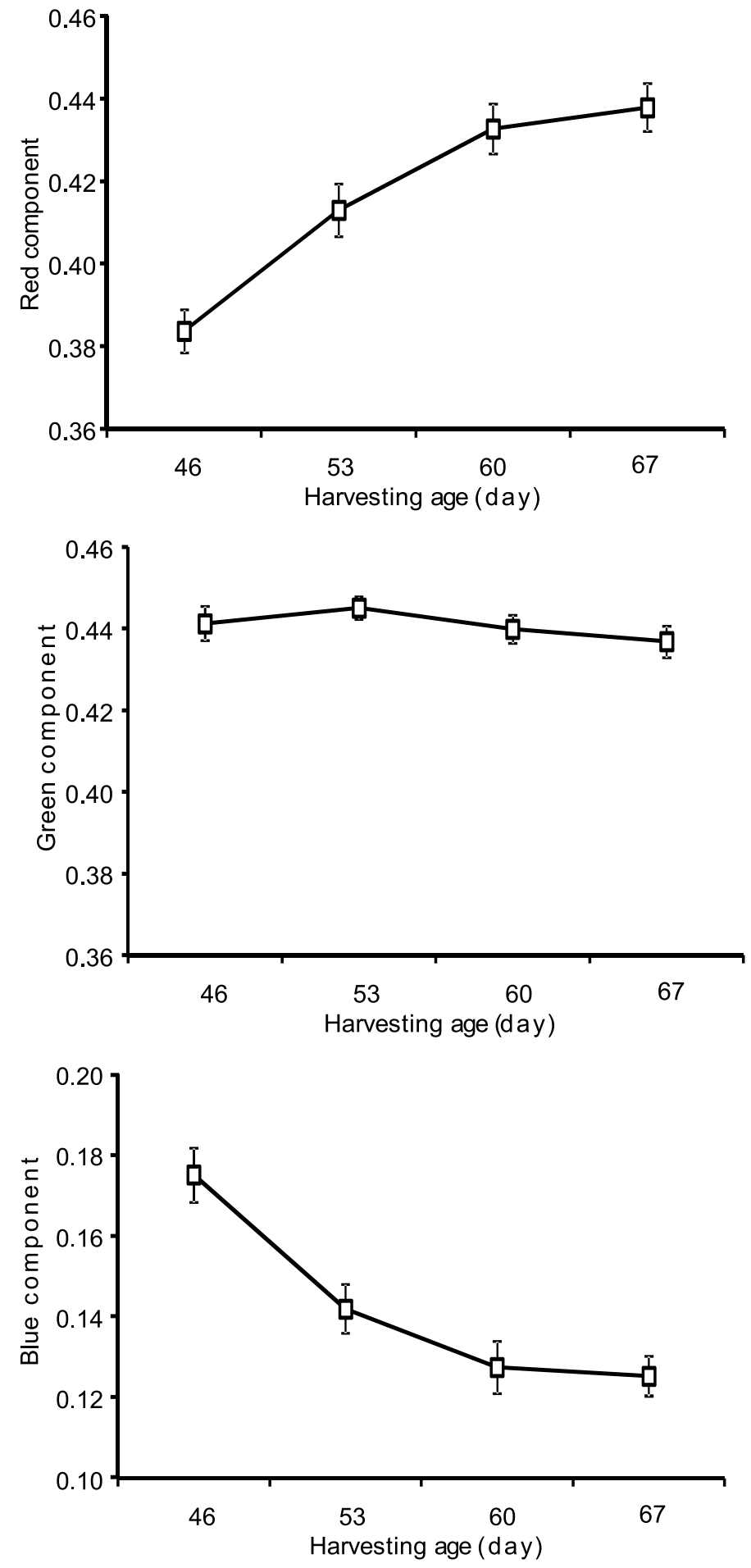

Fig. 3. Change of color of melon skin with harvesting ages measured in RGB color model; (a) red color component, (b) green color component, and (c) blue color component

be separated at 46 and 53 DAP with minimal overlap, but not at 60 and 67 DAP. This also indicated that HSI color distribution could not be used to distinguish melons at 60 and 67 DAP.

To overcome the problem with direct separation using color distribution as explained above, Discriminant Analysis (DA) was applied as a new approach for ripeness separation. In applying DA, for each group member was performed to illustrate any noncollinearity between members. Tolerance values for the green and blue components of the RGB color model were larger than 0.1 ( 0.6876 for green and 0.7553 for blue), while for HSI only 

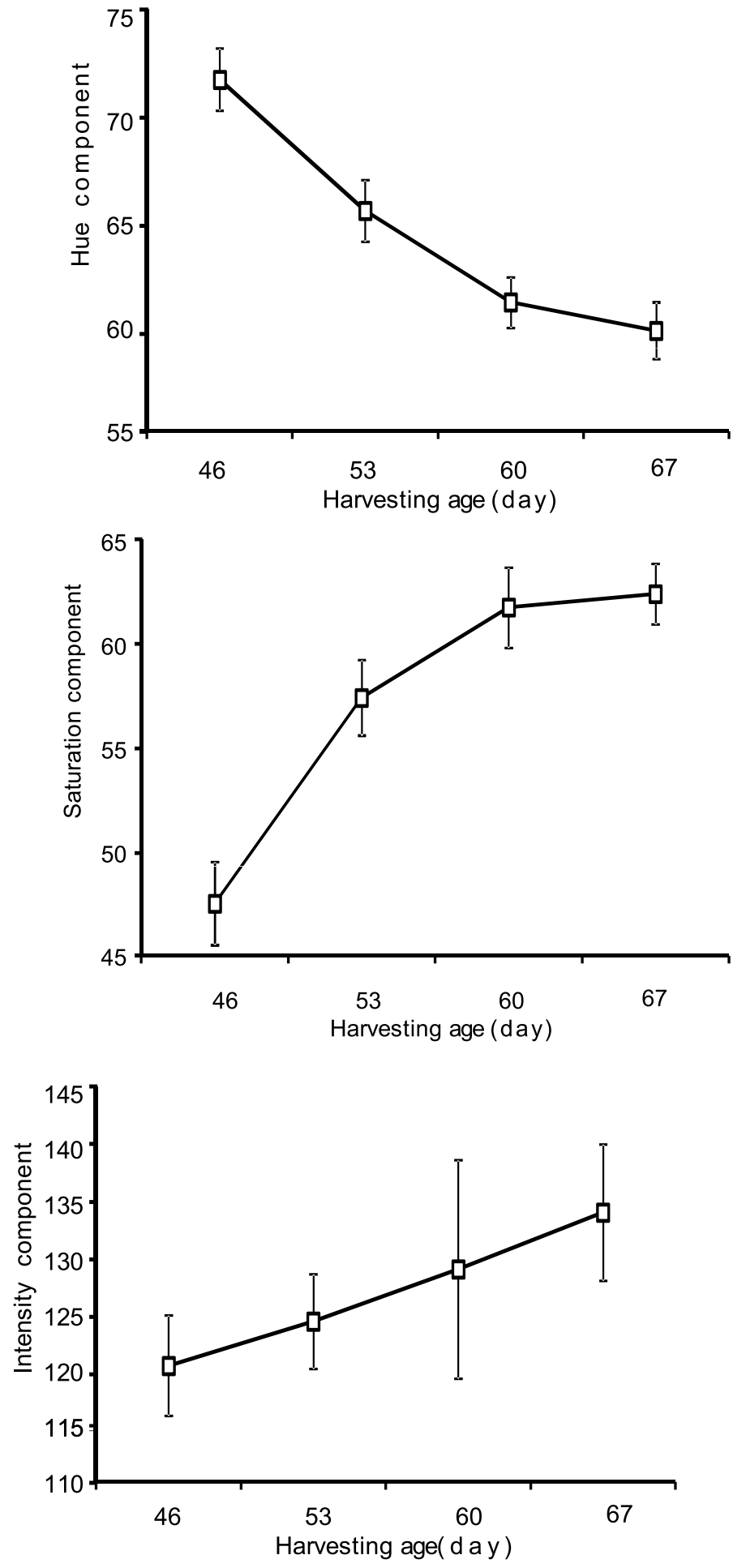

Fig. 4. Change of color of melon skin with harvesting ages measured in HSI color model; (a) hue component, (b) saturation component, and (c) intensity component

intensity was larger than $0.1(0.5439)$. It indicated that green and blue of the RGB color model and intensity of the HSI color model could be further analyzed, while the rest color components could not be analyzed from the two color models. The VIF (variance inflation factor) values were less than 10.0 for all three components as shown in Table 1 . These results indicated that all the three components were suitable for DA since there was no collinearity betwen them. The results were also checked using a quantile-quantile or q-q plot, an exploratory graphical device

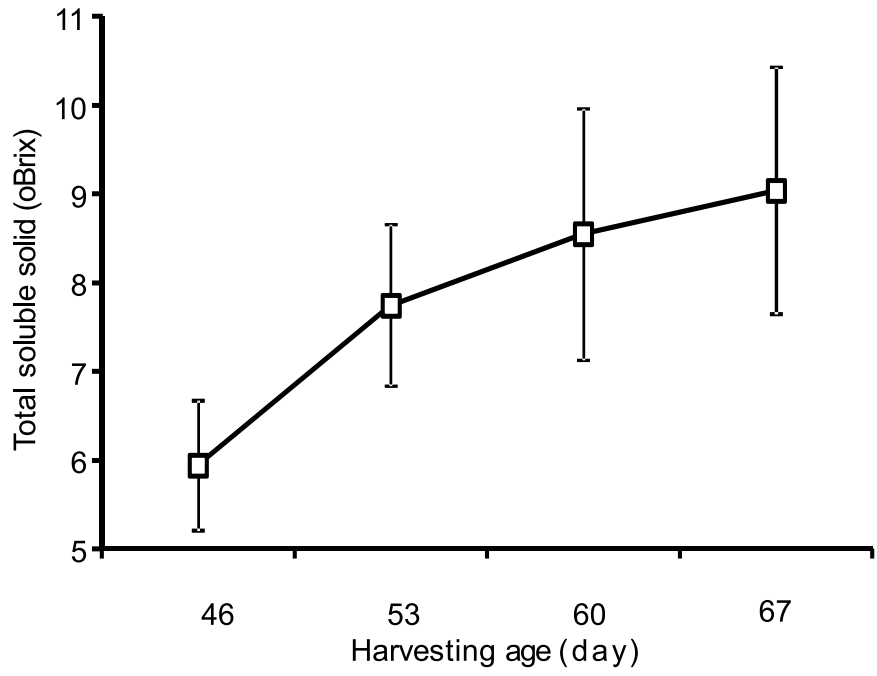

Fig. 5. Change of TSS with harvesting ages measured using hand refractometer Fig. 5. Change of TSS with harvesting ages measured using hand refractometer

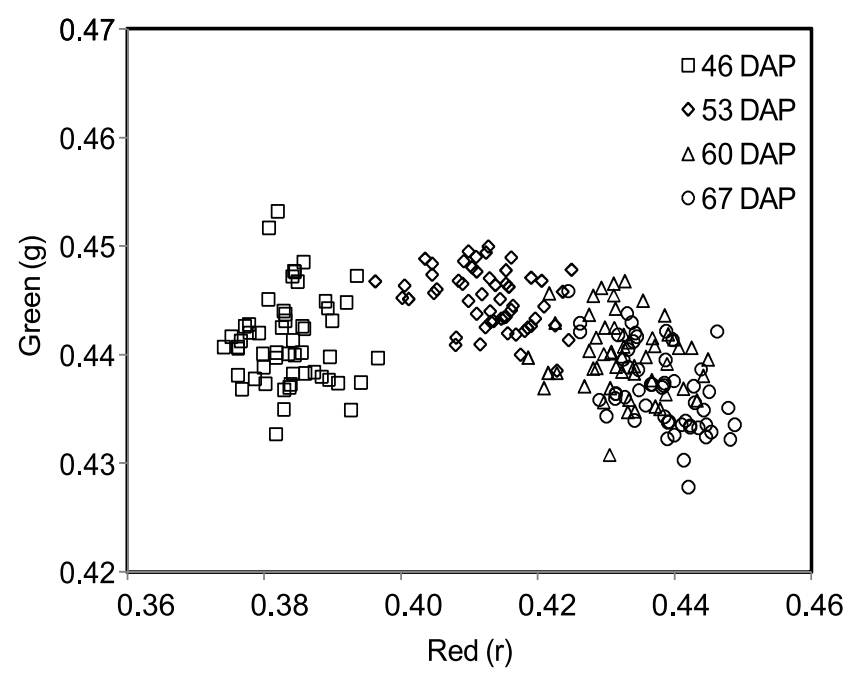

Fig. 6. Green-red color distribution in RGB color model of melon at several harvesting age as results of image analysis

used to check the validity of a distributional assumption for a data set (Fig. 10). Motulsk (2013) has reported that in general, the basic idea is to compute the theoretically expected value for each data point based on the distribution in question. If the data indeed follows the assumed distribution, then the points on the q-q plot is fall approximately on a straight line.

Table 1. Results of multicolinearity statistical analysis

\begin{tabular}{lccc}
\hline Parameter & $\mathrm{G}$ & $\mathrm{B}$ & $\mathrm{I}$ \\
\hline Tolerance & 0.6876 & 0.7553 & 0.5439 \\
VIF & 1.4543 & 1.3239 & 1.8386 \\
\hline
\end{tabular}

The Fisher's box test shows that the p-value (0.0001) was less than alpha (0.05). This indicated that the data for the variables were not homogenous which was suitable for data processing using DA method. Finally, the Fisher discriminant function coefficients, as shown in Table 2, were used to calculate the probability values to demonstrate and showed that the covariance matrices of green, blue, and intensity data were not homogenous as well.

Four equations were developed using variables and coefficients determined in Table 2. Then the four equations were tested by inputting the values of G, B, and I extracted from each image, 
Table 2. Fisher classification functions

\begin{tabular}{lrrrr}
\hline Parameter & \multicolumn{4}{c}{ Harvesting age (DAP) } \\
\cline { 2 - 5 } & \multicolumn{1}{c}{46} & \multicolumn{1}{c}{53} & \multicolumn{1}{c}{60} & \multicolumn{1}{c}{67} \\
\hline Intercept & -39086.97 & -19823.05 & -14491.43 & -8252.95 \\
$\mathrm{G}$ & 131703.46 & 78743.26 & 60142.31 & 34292.33 \\
$\mathrm{~B}$ & 60612.89 & 8402.87 & 9157.88 & 2943.39 \\
$\mathrm{I}$ & 78.56 & 27.49 & 10.62 & 8.74 \\
$\mathrm{G}^{2}$ & -113163.37 & -81225.57 & -63294.62 & -37307.71 \\
$\mathrm{G}^{*} \mathrm{~B}$ & -96686.05 & -8729.54 & -13655.13 & 2265.27 \\
$\mathrm{G}^{*} \mathrm{I}$ & -123.74 & -41.75 & -20.99 & -14.77 \\
$\mathrm{~B}^{2}$ & -31923.70 & -13854.83 & -14906.64 & -28350.57 \\
$\mathrm{~B}^{*} \mathrm{I}$ & -56.22 & -4.70 & 5.02 & 23.63 \\
$\mathrm{I}^{2}$ & -0.06 & -0.03 & -0.01 & -0.02 \\
\hline
\end{tabular}

with the resulting values ranging from a 0 to 1 probability. The four equations are:

$\mathrm{y}_{46}=131703.46 \mathrm{G}+60612.89 B+78.56 I-113163.37 \mathrm{G}^{2}-96686.05 G B-123.74 \mathrm{G} I-$ $31923.70 B^{2}-56.22 B I-0.06 I^{2}$

$\mathrm{y}_{53}=78743.26 \mathrm{G}+8402.87 B+27.49 I-81225.57 \mathrm{G}^{2}-8729.54 G B-41.75 \mathrm{G} I-13854.83 B^{2}$ $-4.70 B I-0.03 I^{2}$

$\mathrm{y}_{60}=60142.31 \mathrm{G}+9157.88 B+10.62 I-63294.62 \mathrm{G}^{2}-13655.13 G B-20.99 \mathrm{G} I-14906.64 B^{2}$ $+5.02 B I-0.01 I^{2}$

$\mathrm{y}_{67}=34292.33 \mathrm{G}+2943.39 B+8.74 I-37307.71 \mathrm{G}^{2}+2265.27 G B-14.77 \mathrm{G} I-28350.57 B^{2}$ $+23.63 B I-0.02 I^{2}$

(4)

where, $\mathrm{y}_{46}, \mathrm{y}_{53}, \mathrm{y}_{60}$, and $\mathrm{y}_{67}$ are the groups of harvesting ages and $\mathrm{B}, \mathrm{G}$, and I are the values of blue component, green component and intensity component obtained from image processing.

In every case, only one function among the four functions (equations 1 to 4 ) gave a value of 1 or near to 1 as a result, and the other three functions gave 0 or near to zero values. The melons were grouped into the group where the function gave a value of 1 or near to 1 . The results of harvesting ages classification using the four equations are shown in Table 3.

Table 3. Real harvesting age groups and predicted groups using DA

\begin{tabular}{ccccccc}
\hline $\begin{array}{c}\text { Real } \\
\text { harvesting } \\
\text { age }\end{array}$ & \multicolumn{4}{c}{$\begin{array}{c}\text { Predicted harvesting age } \\
\text { (DAP) }\end{array}$} & $\begin{array}{c}\text { Total } \\
\text { sample }\end{array}$ & Accuracy (\%) \\
\cline { 2 - 5 } & 46 & 53 & 60 & 67 & & \\
\hline 46 & 55 & 0 & 0 & 0 & 55 & 100 \\
53 & 0 & 53 & 2 & 0 & 55 & 96 \\
60 & 0 & 1 & 35 & 19 & 55 & 63 \\
67 & 0 & 0 & 8 & 47 & 55 & 85 \\
\hline Total & 55 & 54 & 45 & 66 & 220 & 86 \\
\hline
\end{tabular}

From Table 3, it was clear that DA could discriminate harvesting age into four groups with an accuracy of $100 \%, 96 \%, 63 \%$ and $85 \%$ for the 46, 53, 60 and 67 DAP groups respectively. It was noticed that DA could accurately discriminate for the 46 and 53 DAP groups, but not accurate for the 60 and 67 DAP groups. The reason for this might be simply because no clear change in melon skin color occurred at 60 and 67 DAP, and reflected in the relatively smaller change in TSS during this period (Fig. 5). It suggested melons harvested at 60 DAP are already ripe and only a small increase in TSS value could be expected for later harvest.

Another way to ensure the results of the Fisher classication method was with F1, F2, and F3. To find what function would be usefull for DA, the discrimination functions were plotted (Fig. 11). This showed that F1 alone was enough for discrimintaion,

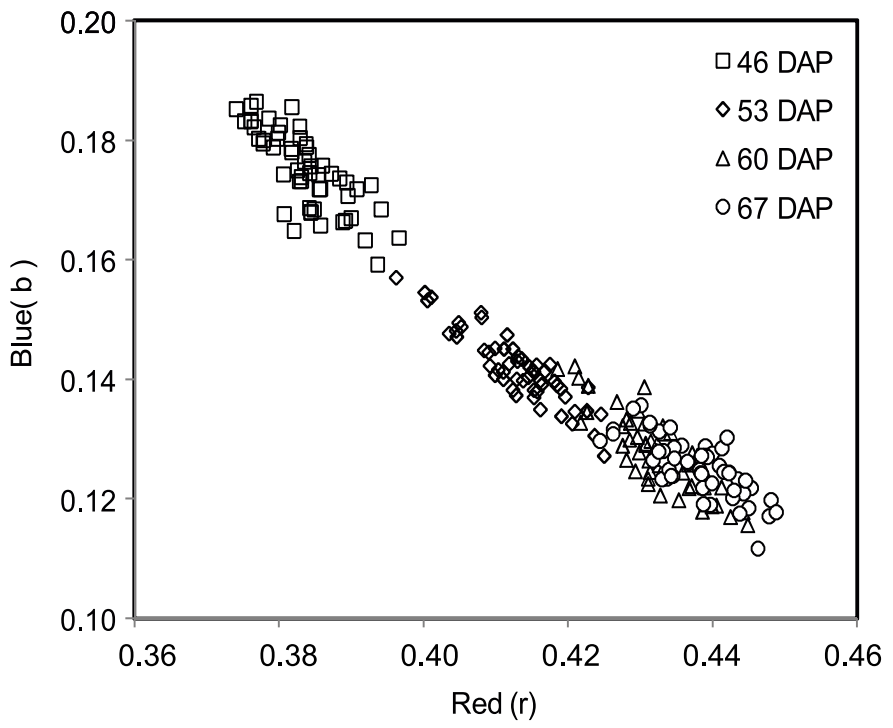

Fig. 7. Blue-red color distribution in RGB color model of melon at several harvesting age as results of image analysis

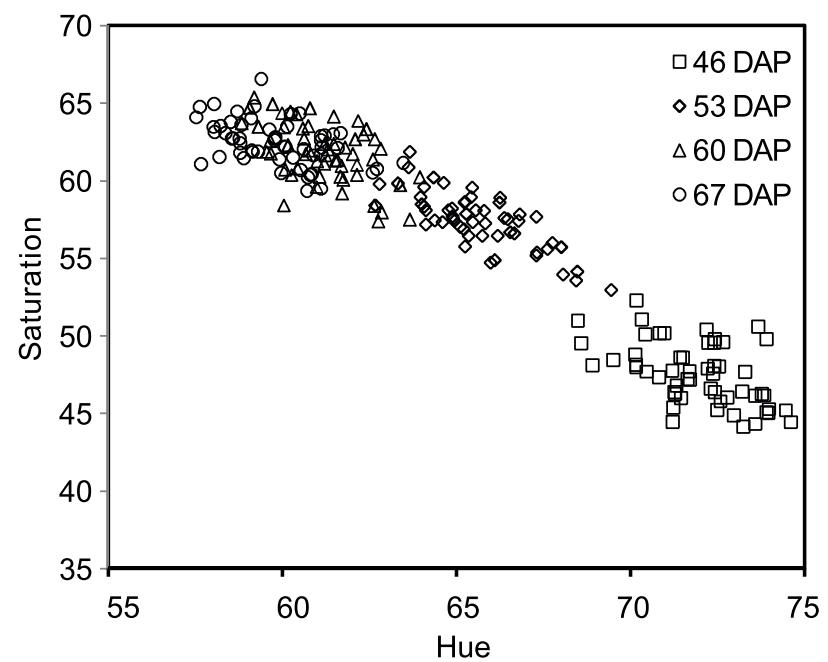

Fig. 8. Saturation-hue color distribution in HSI color model of melon at several harvesting age as results of image analysis

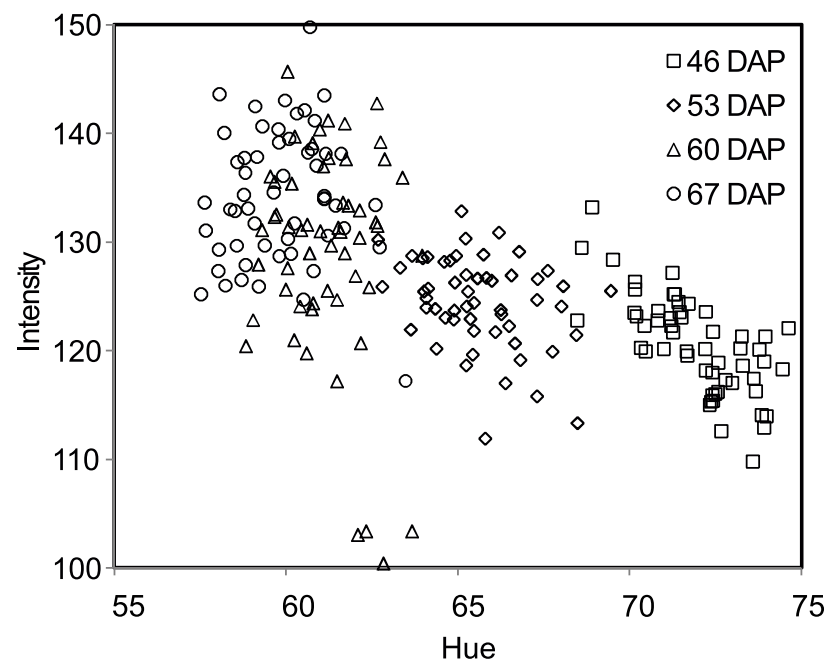

Fig. 9. Intensity-hue color distribution distribution in HSI color model of melon at several harvesting age as results of image analysis

with a slight increase to $99.86 \%$ discrimination when F2 was included, while F3 remained unused. Another criterion was the bi-plot correlation (Fig. 12), which showed the three variables (green, blue, and intensity) are not inline each other for the two 


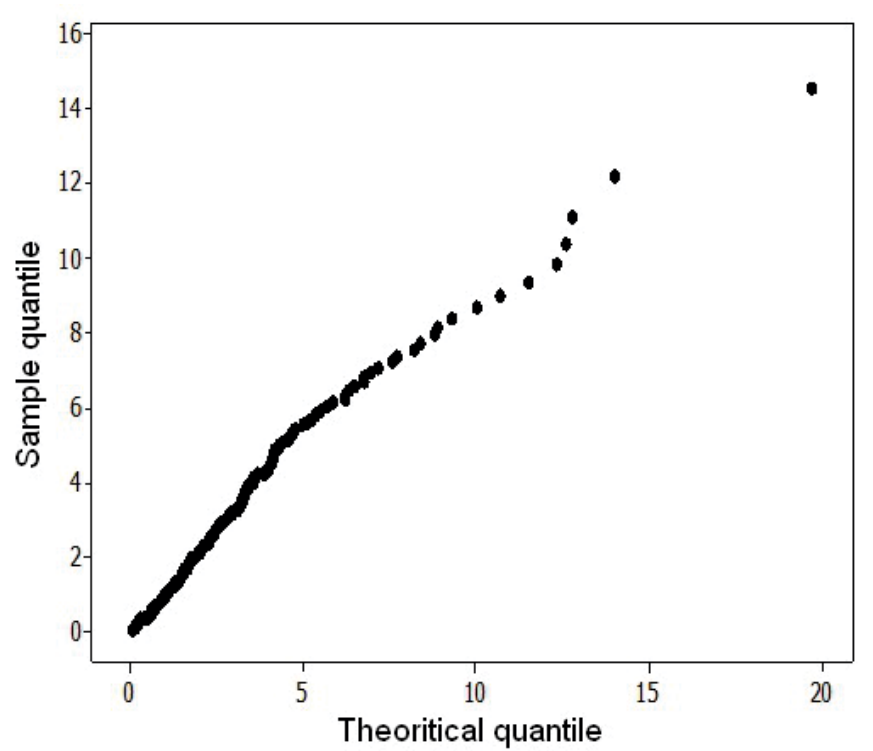

Fig. 10. Result of q-q plot of green, blue, and intensity data from image analysis

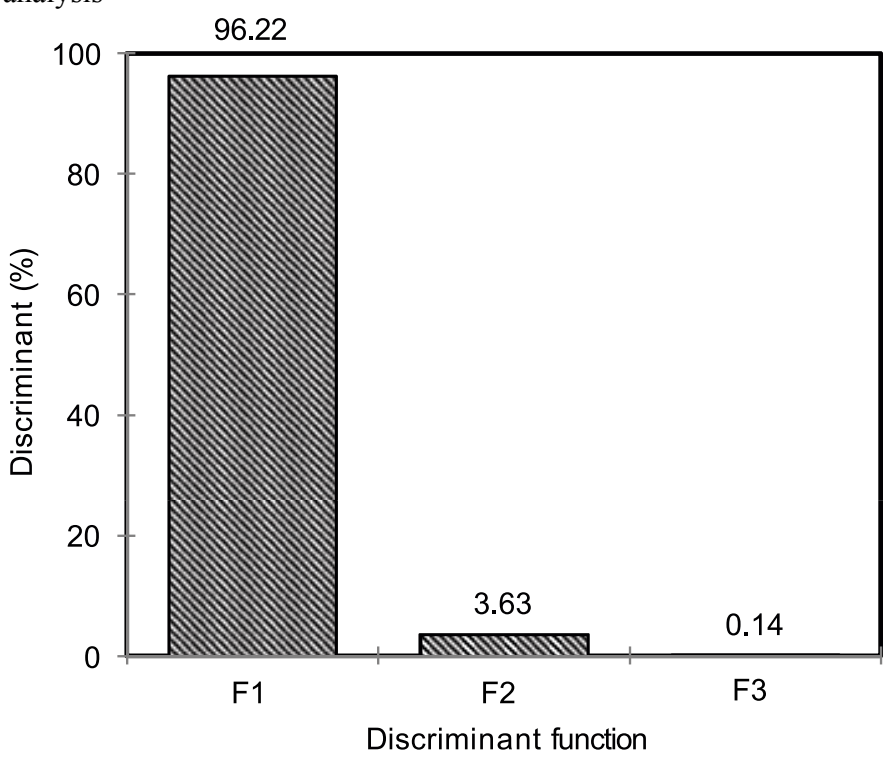

Fig. 11. Principal components for discrimination functions

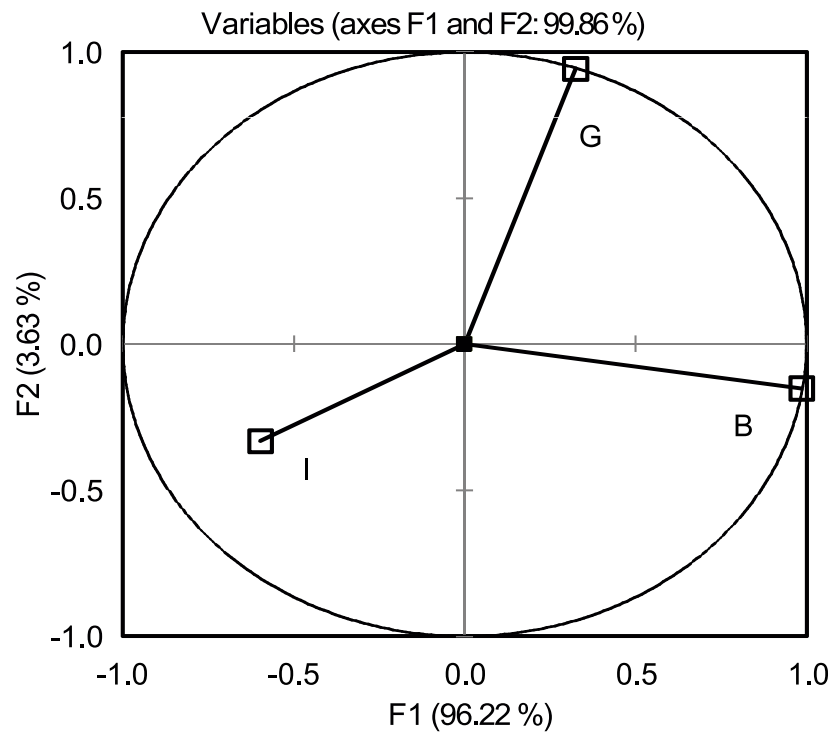

Fig. 12. Bi-plot correlation of green, blue, and intensity

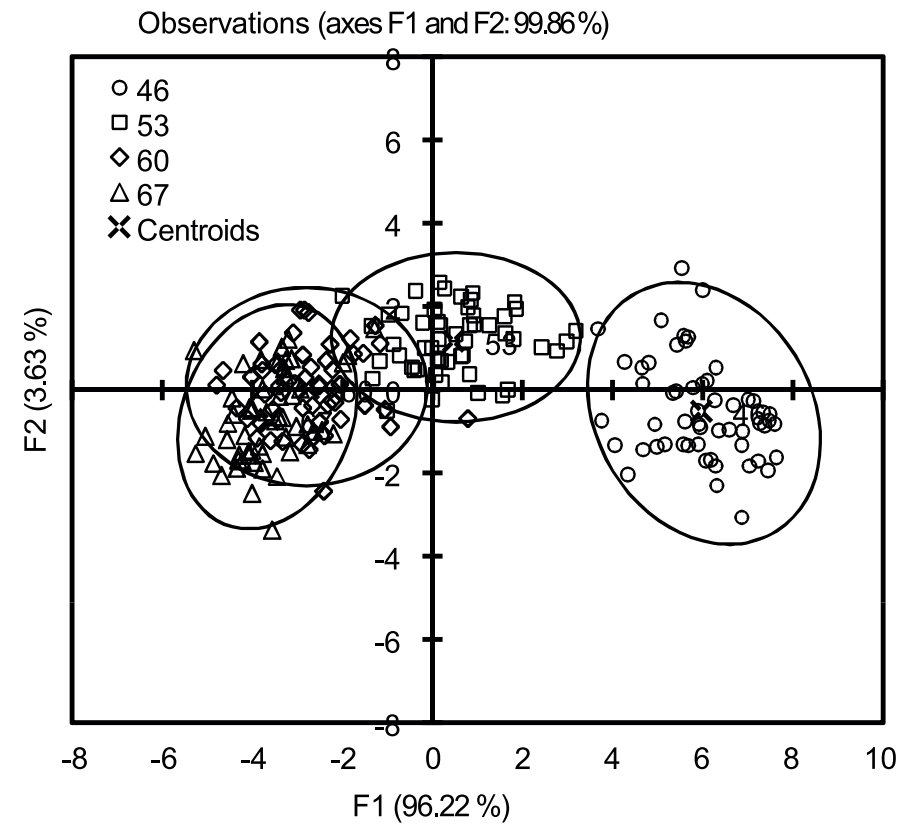

Fig. 13. Plot of discrimination function to predict a group of samples functions (F1 and F2), indicating the variables were eligible for discrimination. Canonical discriminant function coefficients (Table 4) were used to develop a Canonical discriminant function, the results of which are plotted in Fig. 13.

Table 4. Canonical discriminant function coefficients

\begin{tabular}{crrr}
\hline Parameter & \multicolumn{3}{c}{ Discriminant function } \\
\cline { 2 - 4 } & \multicolumn{1}{c}{ F1 } & F2 & \multicolumn{1}{c}{ F3 } \\
\hline Intercept & -62.3984 & -123.2831 & -79.6778 \\
G & 97.9426 & 280.1924 & 124.0657 \\
B & 172.8325 & -16.5531 & 30.3893 \\
I & -0.0424 & 0.0168 & 0.1626 \\
\hline
\end{tabular}

As seen in Fig. 13, the 46 DAP group was clearly separated from the other three groups, while the 53 DAP group slightly overlaps with that of the 60 DAP group. The 60 and 67 DAP groups have a substantial overlap. These results were in agreement with the results of the classification using discriminant functions based Fisher classification functions, as discussed before in this paper.

All methods of data processing showed that ripening at Golden Apollo melon used as samples in this study happened at 60 days after planting. Functions developed using DA could be used to discriminate that ripeness state from other two groups which were not ripen (46 and 53 DAP). Harvesting after 60 DAP might not suitable because increasing in TSS and color was not significant, while wasting time and increasing risk of any damage of melon by insect and diseases. If that the case, there was no necessity to distinguish 60 and 67 DAP. This study demonstrated that the melon could be harvested when they entered the ripening stage at 60 DAP.

From total soluble solid content, Golden Apollo melon fruits started to ripen since 60 days after planting, with total soluble solids slightly increased. Color image analysis of the melons in combination with discriminant analysis could be used to distiguish between harvesting ages of 46, 53, 60, and 67 days after planting with an average accuracy of $86 \%$. However, the developed method could not distinguish melons harvested at 60 and 67 days after planting with a high accuracy, as both groups of melons had already entered the ripening stage. 


\section{Acknowledgement}

Thanks are extended to Garry Piller, a visiting professor at Kyoto University, Japan, and Dr. Subramaniam Sathivel, Department of Biological \& Agricultural Engineering, LSU Agricultural Center, Baton Rouge, USA, for their English editing and proof reading of the manuscript.

\section{References}

Ahmad, U., 2013. Teknologi Penanganan Pascapanen Buahan dan Sayuran. Graha Ilmu Publisher, Yogyakarta, Indonesia.

Ahmad, U., Mardison, R. Tjahjohutomo, and A. Nurhasanah, 2010. Development of automatic grading machine prototype for citrus using image processing. Austral. J. of Agr. Eng., Vol. 1(5): p165-169.

Blasco, J., N. Aleixos, \& E. Molto. 2003. Machine vision system for automatic quality grading of fruit. Biosystems Eng. 85: 415-423.

Costa, C., F. Antonucci, F. Pallottino, J. Aguzzi, D.W. Sun and P. Menesatti, 2011. Shape analysis of agricultural products: a review of recent research advances and potential application to computer vision. Food and Bioprocess Technol. 4: 673-692.

Cubero, S., N. Aleixos, E. Molto, J. Gomez-Sanchis and J. Blasco, 2011. Advances in machine vision applications for automatic inspection and quality evaluation of fruits and vegetables. Food and Bioprocess Technol. 4: 487-504.

Indonesia Beurau of Statistics (BPS), 2015. National fruits production. Biro Pusat Statistik, Jakarta.

Iqbal, A., N.A. Valous, F. Mendoza, D.W. Sun and P. Allen, 2010. Classification of pre-sliced pork and Turkey ham qualities based on image colour and textural features and their relationships with consumer responses. Meat Science, 84: 455-465.
Kays, S.J., 1991. Postharvest physiology of perishable plant products. New York: Van Nostrand Reinholt.

Kays, S.J., 1999. Preharvest factors affecting appearance. Postharvest Biology and Technol., 15: 233-247.

Mahirah J., K. Yamamoto, M. Miyamoto, N. Kondo, Y. Ogawa, T. Suzuki, H. Habaragamuwa, and U. Ahmad. 2015. Double lighting machine vision system to monitor harvested paddy grain quality during headfeeding combine harvester operation. Machines, 3(4): p352-363.

McCaig, T.N. 2002. Extending the use of visible/near-infrared reflectance spectrophotometers to measure colour of food and agricultural products. Food Research Int., 35: 731-736.

Motulsk, H. 2013. Q-Q normality plot. Graph Pad Software Inc.

Pallottino, F., P. Menesatti, C. Costa, G. Paglia, F.R. De Salvador and D. Pascale, 2003. A review of RGB color spaces. Montreal: The Babel Color Company.

Quevedo, R.A., J.M. Aguilera and F. Pedreschi, 2010. Color of salmon fillets by computer vision and sensory panel. Food and Bioprocess Technol., 3: 637-643.

Rocha, A.M.C.N. and A.M.M.B. Morais, 2003. Shelf life of minimally processed apple (cv. Jonagored) determined by colour changes. Food Control, 14; 13-20.

Soedibyo, D.W., K.B. Seminar, U. Ahmad and I.D.M. Subrata, 2010. The development of automatic coffee sorting system based on image processing and artificial neural network. Proc. of AFITA Int. Conf:: The Quality Information for Competitive Agr.icultural Based Production System and Commerce, Bogor, West Java-Indonesia, p272-275. 